\title{
Transfers from prison for urgent psychiatric treatment: a study of section 48 admissions
}

\author{
Jeanette Smith, Caitriona Crowe, Christine Johnson, Martin Donovan
}

The problem of mentally disordered remand prisoners is well recognised and has recently received much publicity. It is currently government policy to divert such offenders from the criminal justice system. ${ }^{1}$ Possible solutions include cautioning by the police or psychiatric treatment either on a voluntary basis or as a civilly detained patient. Joseph and Potter described how mentally disordered defendants could be diverted from custody and criminal cases discontinued by providing psychiatric assessments to magistrates' courts. ${ }^{2}$ Nevertheless, in certain rural areas such a system may not be practical, and for the more serious offender custodial remand is often inevitable.

\section{Section 48}

In the United Kingdom it is generally agreed that prison "hospitals" are not the appropriate place to treat disturbed psychotic individuals. Recent reports have encouraged the use of section 48 of the Mental Health Act $1983^{13}$ when appropriate for this group of offenders. Under section 48 a person remanded in custody and awaiting trial who is suffering from a mental illness or severe mental impairment may be transferred to hospital for psychiatric treatment on the recommendations of two medical practitioners, one of whom must be approved under section 12 of the Mental Health Act. The disorder must be of a nature and degree which make it appropriate for the defendant to be detained in hospital for urgent treatment. The Home Secretary may then direct the person into hospital by issuing a warrant. In all cases the additional provisions of a restriction order apply. The transfer must take place within 14 days and the order is of unspecified duration. It ceases when the court deals with the case or if the patient no longer requires treatment or if it is agreed that no effective treatment can be given at the hospital to which she or he has been remanded. Patients may apply to a mental health review tribunal immediately, and if the order is then discharged the defendant is returned to the prison, pending a court appearance.

Although a potentially very useful provision, there is

Butler Clinic, Langdon Hospital, Dawlish, Devon EX7 ONR

Jeanette Smith, senior registrar in forensic psychiatry Caitriona Crowe, registrar in forensic psychiatry Christine Johnson, registrar in forensic psychiatry Martin Donovan, consultant forensic psychiatrist

Correspondence to: Dr Donovan.

BMF 1992;304:967-9 little available information on the use of section 48 . In this paper a series of patients admitted to a regional secure unit (the Butler Clinic) under this provision is presented and the national data on section 48 transfers from prison examined.

\section{Section 48 admissions to Butler Clinic}

The Butler Clinic, which opened in May 1983, is a 30 bedded regional secure unit covering the catchment area of Devon and Cornwall (population 1.5 million). It is a medium secure facility catering for male and female patients who may need to be managed in a highly staffed unit for up to 18 months. All patients are detained under the Mental Health Act.
Between May 1983 and May 1991 there were 235 admissions to the clinic. Of these, 20 were admitted under the provisions of section 48 of the Mental Health Act. The respective annual figures for 1985 to 1990 were one, three, one, three, four, and seven cases. The mean age of the patients was 33.5 years (range 19-51). Only three of the section 48 admissions were women.

The primary diagnoses of the 20 patients were schizophrenia (12 cases), affective psychosis (six), and drug induced psychosis (two). Most patients also had a degree of personality disturbance. Reasons given for transfer to hospital for urgent treatment included psychotic symptoms associated with violent or threatening behaviour (13 cases), major depressive disorder accompanied by refusal to eat or drink (four), and major depressive disorder with prominent suicidal ideation (three). All but three of the section 48 patients had a previous psychiatric history. Patients spent an average of $25 \cdot 2$ days (range 7-62) remanded in custody before being transferred to hospital. Once in hospital the mean duration of section 48 stay was 131 days (range 35-248).

The index offences for the section 48 admissions included murder (two cases), attempted murder (one), assault occasioning grevious bodily harm or wounding with intent (five), assault occasioning actual bodily harm (four), criminal damage (four), firearms offences (two), deception (one), and unknown (one).

\section{ORDERS UNDER OTHER SECTIONS}

Thirteen of the 20 patients admitted under section 48 were subsequently placed on hospital orders (section 37 ), and in two cases a Home Office restriction order was added (section 41). Four patients were transferred to local hospitals, two as informal patients after the Crown Prosecution Service decided to drop the charges against them and two patients were bailed to await trial. One patient was regraded to section 3 of the Mental Health Act but remained at the Butler Clinic after the charges against her were dropped. One man was put on a probation order with condition of psychiatric treatment, and one was returned to custody once the drug induced psychosis had subsided.

The patients admitted to the Butler Clinic under section 48 were predominantly young, male, and suffering with psychosis. This is largely representative of admissions generally to the clinic. ${ }^{4}$ Reasons given for urgent transfer to hospital indicate a uniformly severe degree of disturbance associated with risks to the health and safety of either the defendant or others. For many section 48 patients the time spent in hospital before their cases were dealt with by the court was prolonged, reflecting the time taken for their mental state to improve sufficiently for a court appearance. The section 48 provision was used in cases awaiting commital to crown court, who were too ill to remain in prison until a section 36 order could be made.

Section 36 is a remand to hospital for treatment 
which can be made only by a crown court and cannot be applied to defendants charged with murder. As two of the patients in this series fell into the latter category the option of section 36 did not exist. Even for those appearing before a magistrates' court and therefore likely to be dealt with more quickly the severity of their mental disturbance precluded a court appearance and required very urgent transfer to hospital. In some cases the section 48 was terminated when the charges were dropped rather than when the patient's mental state had improved. Although a hospital order was the outcome in only just over half of cases, it is of note that only one patient was returned to prison.

Although some of the patients had committed relatively minor offences, it is of interest that almost half of the patients had committed very serious violent offences. Although the current emphasis on diverting the mentally disordered from the criminal justice system at an early stage may be applicable to the majority of mentally ill offenders, for those who have committed serious offences this is only rarely realistic. The section 48 provision is a viable alternative for this group, provided secure psychiatric facilities are available.

A potential defect of the section 48 provision, from a criminal justice point of view, is that the right of the defendant to a proper trial may not be safeguarded. ${ }^{5}$ Section 51 of the Mental Health Act 1983 allows a hospital order with or without restrictions to be made in the patient's absence without recording a conviction if, after considering depositions, the court considers it appropriate to make an order. This is in contrast with those who are remanded to hospital under section 35 or 36 , who remain in hospital for a maximum of three months and have to return to court for a trial and sentencing. Although this possibility exists, in the present series of section 48 patients it did not occur.

\section{Section 48 admissions in South Western region}

Between 1983 and 1990 there were 46 admissions to hospital in the South Western region under the provisions of section 48. In the four years between 1983 and 1987 there were only 10 section 48 admissions, and five of these came to the Butler Clinic. In 1988 the second regional secure unit in the south west-the Fromeside Clinic-opened. This unit was located in Bristol and covered the catchment areas of Somerset, Avon, and Gloucester. In the three years from 1988 until 1990 the remaining 36 admissions under section 48 occurred. Of these, 14 were to the Butler Clinic, 14 to the Fromeside Clinic, and eight to local psychiatric hospitals.

\section{Section 48 admissions in England and Wales}

Between 1983 and 1990 there were 580 admissions in England and Wales under the provisions of section 48. Table I shows the variations in the annual section 48 admissions. Eighty (14\%) patients were admitted to one of the special hospitals. In 1990 there were 172 section 48 admissions to hospitals in England and Wales. Table II shows the variation in the use of section 48 between regional health authorities.

TABLE II-Section 48 admissions by regional health authority during 1990

\begin{tabular}{lc}
\hline Regional health authority & $\begin{array}{c}\text { No of } \\
\text { admissions }\end{array}$ \\
\hline South Western & 24 \\
West Midlands & 19 \\
Yorkshire & 17 \\
Special hospitals & 16 \\
Northern & 14 \\
North East Thames & 14 \\
Trent & 13 \\
North West Thames & 11 \\
North Western & 10 \\
Wessex & 8 \\
South East Thames & 8 \\
Mersey & 6 \\
South West Thames & 3 \\
Oxford & 2 \\
Wales & 2 \\
Private hospitals (via North East Thames) & 2 \\
East Anglian & 1 \\
Special health authority & 1 \\
Not known & 1
\end{tabular}

\section{Interpreting the data}

The figures for the Butler Clinic, the South Western region, and England and Wales strongly indicate a trend towards increasing use of section 48 of the Mental Health Act. However, there is considerable variation in the use of this provision between regions. Interestingly, although the total numbers of patients being admitted to special hospitals is increasing, there is a trend towards a smaller proportion of the national section 48 admissions going to maximum security hospitals. There are several possible explanations for these changes in the frequency in usage of section 48 . If it is accepted that it is appropriate to transfer severely ill prisoners in need of urgent treatment to psychiatric units then the increasing use of section 48 generally should be welcomed. It may well be a reflection of the increasing awareness of the problem of mentally disordered prisoners on remand and the substantial risk of suicide in this group. ${ }^{6}$

The development of medium secure facilities is likely to have facilitated the use of section 48 . Table I shows that there has been a fourfold increase in the number of regional secure unit beds nationally since 1983. As the data on the Butler Clinic show, many of these patients have committed very serious offences, and in view of the risk to the public it is often necessary to admit to conditions of security. The large increase in the use of section 48 in the South Western region since the second regional secure unit became functional would also support this theory. Availability of medium secure beds may also partially account for the regional variation in the use of section 48. Possibly in some regions there is a shortage of secure facilities, or

TABLE I-Section 48 admissions 1983-90

\begin{tabular}{|c|c|c|c|c|c|}
\hline Year & $\begin{array}{l}\text { No of section } 48 \\
\text { admissions in England } \\
\text { and Wales }\end{array}$ & $\begin{array}{l}\text { No of section } 48 \\
\text { admissions to special } \\
\text { hospitals }\end{array}$ & $\begin{array}{l}\text { No of regional secure } \\
\text { unit beds in } \\
\text { England and Wales }\end{array}$ & $\begin{array}{l}\text { No of psychiatric beds in } \\
\text { England and Wales }\end{array}$ & $\begin{array}{l}\text { No of psychiatric beds in } \\
\text { South Western region }\end{array}$ \\
\hline 1983 & 10 & 4 & 150 & 81786 & 5095 \\
\hline 1984 & 51 & 9 & 264 & 78911 & 4796 \\
\hline 1985 & 39 & 2 & 375 & 75866 & 4653 \\
\hline 1986 & 51 & 8 & 495 & 72402 & 4261 \\
\hline 1987 & 75 & 16 & 532 & 67127 & 4192 \\
\hline 1988 & 84 & 9 & 576 & 62999 & 3872 \\
\hline 1989 & 98 & 16 & 546 & 59290 & 3629 \\
\hline 1990 & 172 & 16 & $\begin{array}{l}\text { Roughly } 635 \\
\text { (597 staffed) }\end{array}$ & Not known & 3415 \\
\hline Total & 580 & 80 & & & \\
\hline
\end{tabular}


in those which already exist beds have become blocked by chronically disturbed mentally ill patients. The south west has not experienced the latter problem and has therefore virtually always been able to admit prisoners in urgent need of psychiatric treatment. This would appear to be an extremely important use of the regional secure unit, and therefore the ability to run at just below full capacity, thus allowing for emergency admissions from prison, may be desirable.

Nevertheless, there are less favourable interpretations of the data. The increasing use of section 48 may indicate larger numbers of severely mentally ill prisoners on remand. Could this in turn reflect a failure of community psychiatric services and a lack of longer term facilities for the severely mentally ill? Table I shows that both in the south west and nationally the increased use of section 48 has been associated with more than a $30 \%$ reduction in the number of psychiatric beds. Interestingly, nearly all of the section 48 patients in the present series were already known to the psychiatric services. It could be argued that those regions with few section 48 admissions are providing a superior service for this group of patients compared with regions that make greater use of the section 48 provision. Clearly more detailed studies are required to clarify this.

It is unlikely that any straightforward conclusions can be drawn from these data. The relation between the use of section 48 and other factors such as the availability of general psychiatric facilities, secure beds, and the recognition of the need to treat mentally ill offenders outside the prison system is a complex equation. Nevertheless, the use of section 48 should be included as one of the parameters by which the psychiatric services are monitored and should be subject to regular audit. For more serious offenders suffering from mental illness who cannot be diverted from the criminal justice system at an early stage the use of section 48 should be encouraged.

We are very grateful to $\mathrm{Mr}$ Dyce from the $\mathrm{C} 3$ division of the Home Office for providing the national data on section 48 admissions. We also thank Mrs Jenny Peterson for secretarial support.

1 Home Office. Provision for mentally disordered offenders. London: HMSO, 1990 (Home Office circular No 66/90.)

2 Joseph PL, Potter M. Mentally disordered homeless offenders-diversion from custody. Health Trends 1990;22:51-3.

3 British Medical Association. Working party report on the health care of remand prisoners. London: BMA, 1990 .

prisoners. London: BMA, 1990 .
Smith JE, Parker J, Donovan WM. Female admissions to a regional secure unit. fournal of Forensic Psychiatry 1991;2:95-102.

Fournal of Forensic Psychiatry 1991;2:95-102.
Grounds A. Mitigation and treatment. In: Bluglass R, Bowden P, eds. Principles and practice of forensic psychiatry. Edinburgh: Churchill Livingstone, 1990. 6 McClure GMG. Suicide in England and Wales, 1975-84. Br J Psychiatry 1987;150:309-14

(Accepted 21 January 1992)

\section{The Gatekeeper and the Wizard revisited}

\section{Nigel Mathers, Tim Usherwood}

Once upon a time there lived a Gatekeeper and a Wizard. ${ }^{\prime}$ The Gatekeeper lived in a house at the entrance to a great high castle, and in this castle lived the Wizard. The Gatekeeper was very clever and his job was to see all the poorly people and cast his magic spells to make them better. Sometimes, however, the people were so poorly that he couldn't make them better and then he opened the gate into the great high castle so they could see the Wizard. She was also very clever and she too had powerful spells and potions to make the people better. It was a good system but as the Wizard learnt how to cast more powerful spells the number of poorly people waiting to see her grew and grew. The people all cried: "We give the King our money so we can see the Wizard when we're poorly but we are having to wait longer and longer to see her. Why is this?"

The King summoned his Minister. "Pray tell me what is going on?" he demanded.

"Well, Sire," the Minister replied, "although you seem to be spending more money than ever before, that Gatekeeper and Wizard are never satisfied. They keep telling the people that they need more money to run the system and that we don't spend enough compared to other Kings across the sea."

The King stroked his beard and looked thoughtful. "We spend quite enough money on the Gatekeeper and the Wizard as it is," he murmured.

"Why don't we make the Gatekeeper and the Wizard more efficient?" suggested the Minister. "I'm sure that Gatekeeper makes some unnecessary referrals to the Wizard because he can't be bothered to deal with them himself and the Wizard has always got some empty beds in the castle so we could cut down on those as well. I'm sure there's scope for increased efficiency there. We could also close the door of the Counting House two hours earlier each day so they couldn't get money out as quickly."

The King liked what he was hearing.
“And what about an Inspector?” asked the Minister enthusiastically.

"What a splendid idea!" exclaimed the King. "An Inspector is bound to save me money in the long run by finding out just how efficient that Gatekeeper and Wizard are."

"May I suggest a Charter for the poorly people, Sire?”

"Capital!" replied the King. "Tell the people that no one who is quite poorly should have to wait more than two years to see the Wizard."

And so it was done. An Inspector was appointed and the people were given a Charter.

\section{The Inspector makes his visits}

The Gatekeeper was busy as usual when the Inspector arrived. "I can measure how efficient you are by how many poorly people you send to the Wizard and by how many spells you have been casting, some of which I'm sure are unnecessary. I can also compare you with other Gatekeepers at different castles. You must prove to me that you are at least as efficient as they are."

The Gatekeeper felt very cross indeed! He didn't like the Inspector's attitude one bit. Here was an Inspector checking up on him, and soon he would be telling him what to do! "How do you know that what you're measuring actually tells you how efficient I am?" he asked angrily.

"The King pays you so he makes the rules-just prove to me that you're as efficient as the other Gatekeepers across the land and you'll have nothing to fear," answered the Inspector.

"I'm doing my best," thought the Gatekeeper. "I suppose I could throw this Inspector out of my house and never let him in again. Perhaps I could do the measuring and only let him see the things I want him to see. I could even point out that if the Counting House was open for longer each day we might have enough
Nigel Mathers, lecturer lecture

BM于 1992;304:969-71 